\title{
Revised Graphical Tool for ABG Interpretation using Modified Bicarbonate/Standard Bicarbonate Ratio
}

\author{
Dr. T. Rajini Samuel M.D* \\ Assistant Professor of Biochemistry, Shri Sathya Sai Medical College and Research institute, Sri Balaji \\ Vidyapeeth Deemed to be University, Guduvancherry-thiruporur main road Ammapettai, kancheepuram \\ district, Tamilnadu, India.
}

\begin{abstract}
*Corresponding Author: Dr. T. Rajini Samuel M.D, Assistant Professor of Biochemistry, Shri Sathya Sai Medical College and Research institute, Sri Balaji Vidyapeeth Deemed to be University, Guduvancherry-thiruporur main road Ammapettai, kancheepuram district, Tamilnadu, India.
\end{abstract}

\begin{abstract}
Arterial Blood Gas analyser is one of the most important point of care testing in intensive care unit that has immense clinical value in the management of critically ill patients. The technological innovations in Point-of-care devices offer rapid analysis at the patient bed side which produce quick and accurate results. The advancement in the innovations of blood gas analysers that has occurred in the last decades has not brought a respective advance in the field of diagnosis. There are only few graphical visualization tools available for Arterial blood Gas (ABG) interpretation depicting the respiratory and metabolic acid-base disturbances. Davenport or Bicarbonate-pH diagram is a graphical tool to depict the respiratory and metabolic acid-base disturbances which is rarely used in clinical setting. Grogono diagram, despite its higher diagnostic agreement compared to the classic Siggaard-Andersen diagram, is not superior to the Oxygen Status Algorithm software program.
\end{abstract}

The parameters like pH, pCO2, bicarbonate and Standard base excess are routinely utilized for interpretation. The bicarbonate concentration parameter is useful only in patients with normal respiration because it is a variable parameter highly influenced by the changes in the concentration of carbon-dioxide (pCO2). This is solved by measuring Standard bicarbonate. The deviation between these two values denote the respiratory influence. The ratio between bicarbonate and standard bicarbonate value and the differences between bicarbonate/carbonic acid and standard bicarbonate/carbonic acid ratio values render some clues in discriminating various acid base disorders. This concept was applied in a previous research study for the development of a novel four quadrant graphical method for ABG interpretation by the current author using standard base excess values in the $x$ axis and the ratio $\{(\mathrm{HCO} 3$ - Standard HCO3) /carbonic acid $\}$ in the $y$ axis. A minor problem with the ratio $\{(\mathrm{HCO} 3$ - Standard HCO3) /carbonic acid\} is that as the pCO2 increases, this ratio also increases but afterwards the curve flattens and may not clearly differentiate the different higher levels of pCO2 values. The aim of the current research study is to rectify this problem by the construction of the revised four quadrant graphical tool for $A B G$ interpretation.

Keywords: Revised Graphical Tool, ABG Interpretation

\section{INTRODUCTION}

Arterial blood gas analyser is one of the most important point of care testing in intensive care unit and plays a vital role in management of critically ill patients. [I, II] The technological innovations in Point-of-care devices offer rapid analysis at the patient bed side due to its ease-of-use, short turnaround time and portability which produce quick and accurate results. An increase in the number of patients in critical care units and a rise in the burden of chronic diseases like diabetes mellitus, chronic obstructive pulmonary diseases (COPD), asthma, coronary heart disease and renal failure enhanced the requirement of blood gas analysers but the complexity involved in the interpretation of blood gas analysis data act as a restraining factor for the same. [I - IV]

The graphical methods will serve as a supporting tool for teaching purposes for better understanding of the arterial blood gas interpretation. [III, IV] A plenty of methods exist in literature to guide the arterial blood gas $(\mathrm{ABG})$ interpretation. But only few graphical methods are available depicting the respiratory and metabolic acid-base disturbances. [I] 
The measured parameters like $\mathrm{pH}, \mathrm{PCO}_{2}$ and calculated parameters like bicarbonate and Standard base excess are routinely utilized for interpretation. In ABG analysis, $\mathbf{P C O}_{2}$ denotes the respiratory component and bicarbonate and standard base excess represents the metabolic component in physiological and base excess approach respectively. $[\mathrm{V}, \mathrm{VI}]$

As $\mathrm{PCO}_{2}$ increases, it reacts with water molecules to form carbonic acid which dissociates into hydrogen and bicarbonate ions, the reaction catalysed by the enzyme carbonic anhydrase present inside the Red blood cells (RBC). The hydrogen ions are buffered by non-bicarbonate buffers like haemoglobin, albumin and phosphate buffer system. So, the concentration of bicarbonate changes with $\mathrm{PCO}_{2}$ values. So, the concentration of bicarbonate increases with increase in $\mathrm{PCO}_{2}$ and it decreases as the $\mathrm{PCO}_{2}$ value decreases. The measurement of standard bicarbonate helps to solve this problem. Standard bicarbonate is the concentration of bicarbonate in the plasma from blood which is equilibrated with a normal $\mathrm{PaCO}_{2}\left(40 \mathrm{mmHg}\right.$ ) and a normal $\mathrm{pO}_{2}$ (over $100 \mathrm{mmHg}$ ) at a normal temperature $\left(37^{\circ} \mathrm{C}\right)$. [VII-IX]

The actual bicarbonate and the standard bicarbonate concentrations are approximately equal under normal ventilation but in abnormal respiration (either hypoventilation or hyperventilation) the two values alter and deviate from each other depending on the changes in the concentration of $\mathrm{PCO}_{2}$.

The ratios derived using bicarbonate, standard bicarbonate and carbonic acid values render some clues in discriminating various acid base disturbances. These ratios are greatly altered in respiratory disorders and also in metabolic acid-base disturbances associated with respiratory compensations. The alteration of ratio values are minimal in purely metabolic acid-base disturbances without respiratory compensation. [VII]

A novel four quadrant graphical tool was developed by Rajini Samuel (current author) based on this concept for $\mathrm{ABG}$ interpretation using standard base excess and the ratios derived using standard bicarbonate, bicarbonate and carbonic acid that demarcates the various acid base disturbances.[VIII] A minor drawback of this graphical tool is that this may not clearly demarcate the different higher levels of $\mathrm{PCO}_{2}$ values.[I] The aim of the current research article is to construct a revised four quadrant graphical tool to rectify this problem.

\section{Materials ANd Methods}

\subsection{Henderson Hasselbalch Equation}

$$
\text { pH }=\text { pKa }_{2} \mathrm{CO}_{3}+\log \left[\mathrm{HCO}_{3}^{-}\right] /\left[\mathrm{H}_{2} \mathrm{CO}_{3}\right]
$$

$\mathrm{pH}$ is the acidity in the blood, $\mathrm{pK}_{\mathrm{a} \text { H2 }} \mathrm{CO}_{3}$ is the negative logarithm (base 10) of the acid dissociation constant of carbonic acid. It is equal to 6.1 at normal body temperature.

$$
\mathrm{pH}=6.1+\log _{10}\left[\mathrm{HCO}_{3}^{-}\right] /\left[\mathrm{H}_{2} \mathrm{CO}_{3}\right]\left\{\left[\mathrm{H}_{2} \mathrm{CO}_{3}\right]=\boldsymbol{k}_{\mathbf{H C O} 2} \mathrm{X}_{\mathrm{PCO} 2}\right\}=6.1+\log _{10}\left[\mathrm{HCO}_{3}^{-}\right] /\left[0.03 \mathrm{X}_{\mathrm{PCO}_{2}}\right]
$$

$\left[\mathrm{HCO}_{3}{ }^{-}\right]$is the concentration of bicarbonate in the blood $(\mathrm{mEq} / \mathrm{L}$ or $\underline{\mathrm{mmol}} / \mathrm{L}) \mathbf{P a C O}\left(\mathrm{PCO}_{2}\right)$ is the partial pressure of carbon dioxide in the arterial blood $(\mathrm{mm}$ of $\mathrm{Hg}$ )

$\left[\mathrm{H}_{2} \mathrm{CO}_{3}\right]$ is the concentration of carbonic acid in the blood $(\mathrm{mmol} / \mathrm{L})$.

$\boldsymbol{k}_{\boldsymbol{H} \mathrm{CO} 2}$ is a constant including the solubility of carbon dioxide in blood. The solubility coefficient of $\mathrm{CO}_{2}$ value is approximately $\mathbf{0 . 0 3}(\underline{\mathbf{m m o l}} / \underline{\mathbf{L}}) / \mathbf{m m H g}$. The normal bicarbonate and carbonic acid ratio is 20. The ratio is changed under abnormal conditions. [X]

\subsection{Derivation of the Kassirer-Bleich Approximation:}

$$
\mathbf{p H}=\text { pKa }_{2} \mathrm{CO}_{3}+\log \left[\mathrm{HCO}_{3}^{-}\right] /\left[\mathrm{H}_{2} \mathrm{CO}_{3}\right]
$$

The above equation is in logarithm form.

$\mathbf{p H}=-\log \left[\mathrm{H}^{+}\right.$nanomoles $\left./ \mathrm{L}\right] ; \quad \mathbf{p K}_{\mathrm{a}}=-\log \left[\mathrm{K}_{\mathrm{a}}\right] ; \mathrm{K}^{\prime}=\mathbf{1 0}^{-\mathrm{pKa}}$

Where $\mathbf{K}^{\prime}$ is the dissociation constant from the $\mathbf{p K _ { \mathbf { a } }}$ of carbonic acid, 6.1, which is equal to $800 \mathrm{nmol} / \mathrm{L}\left(\right.$ since $\left.\mathrm{K}^{\prime}=10^{-\mathrm{pKa}}=10^{-(6.1)} \approx 8.00 \times 10^{-7} \mathrm{~mol} / \mathrm{L}=800 \mathrm{nmol} / \mathrm{L}\right)$

$[\mathrm{H}+]=\left\{\mathrm{K}^{\prime} *\left(0.03 \mathrm{X}_{\mathrm{PCO} 2}\right)\right\} /\left[\mathrm{HCO}_{3}^{-}\right]$

The Henderson Equation, which is derived from the Law of Mass Action, can be modified with respect to the bicarbonate buffering system to yield a simpler equation that provides a quick approximation of the $\mathrm{H}^{+}$or $\mathrm{HCO}_{3}{ }^{-}$concentration without the need to calculate logarithms. [X]

By multiplying $\mathbf{K}^{\prime}(\mathbf{n m o l} / \mathbf{L})$ and $\mathbf{0 . 0 3}$, the product value is 24 . $(\mathbf{8 0 0} \mathbf{X} \mathbf{0 . 0 3})$

The equation is simplified to: 
$\mathbf{H}^{+}($Hydrogen ion concentration $)=\left\{24 \mathrm{X} \mathrm{PCO}_{2}\right\} / \mathrm{HCO}_{3}$

The concentration of bicarbonate is calculated using this Modified Henderson Equation in the ABG analyser.[X,XI,XII]

\subsection{Calculation of $\mathrm{PH}$ from Calculated $[\mathrm{H}+]$}

$\mathbf{H}^{+}($Hydrogen ion concentration at actual pH $)=\left\{24 \mathrm{X} \mathrm{PCO}_{2}\right\} / \mathrm{HCO}_{3}$

This is calculated using Modified Henderson Equation. [X,XI,XII]

pH $=-\log \left[\mathrm{H}^{+}\right.$nanomoles $\left./ \mathrm{L}\right]$

$=-\log \left[\mathrm{H}^{+} \mathrm{x} \quad 10^{-9}\right.$ moles $\left./ \mathrm{L}\right]$

$=-\log \left[\mathrm{H}^{+}\right]-\log \left[10^{-9}\right]$

$\left\{\right.$ nanomoles $\left./ \mathrm{L}=10^{-9} \mathrm{moles} / \mathrm{L}\right\}$

pH $=9-\log \left[\mathrm{H}^{+}\right]$

Using this relationship, the $\mathrm{pH}$ can be calculated from the hydrogen ion concentration. [XI,XII]

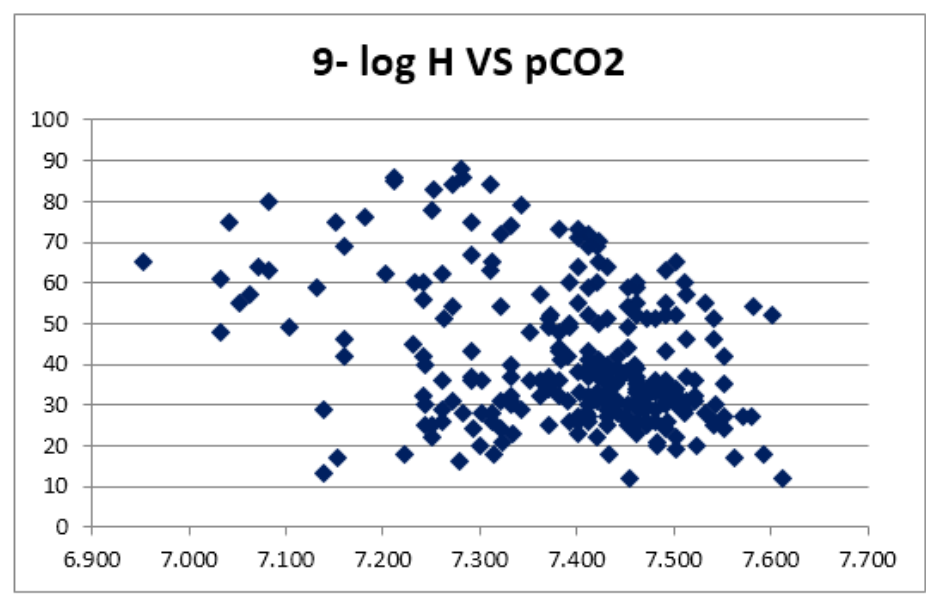

GRAPH1. $\mathrm{X}$ : axis 9- $\log \mathrm{H}$ VS Y: axis $\mathrm{PCO}_{2}$

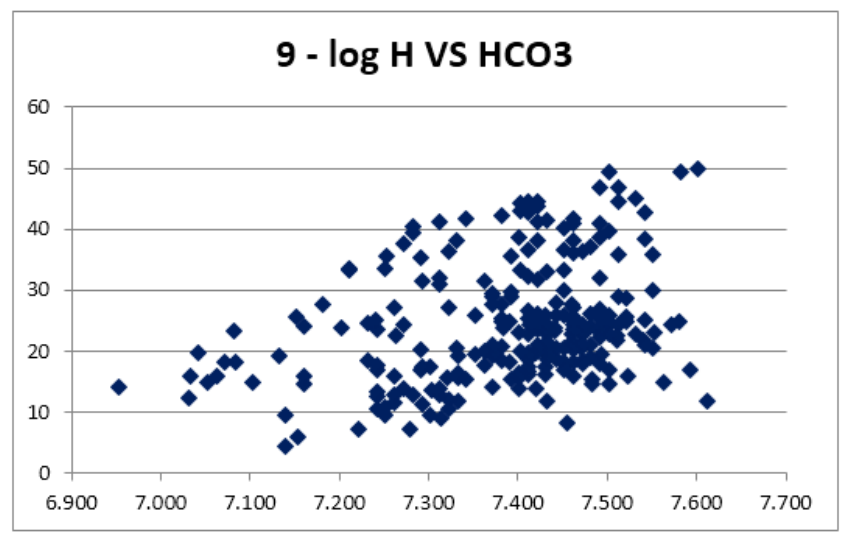

GRAPH2. X: axis $9-\log H$ VS Y: axis $\mathrm{HCO}$

It is found there is no clear relationship between $\mathrm{pH}$ and partial pressure of carbon dioxide $\left(\mathrm{PCO}_{2}\right)$ values (shown in graph 1) and $\mathrm{pH}$ and bicarbonate concentration values (shown in graph 2).[X]

\subsection{Calculation of Bicarbonate/Carbonic Acid Ratio}

The carbonic acid concentration $(\mathrm{mmol} / \mathrm{L})$ was calculated by the given formula.

$$
\mathrm{H}_{2} \mathrm{CO}_{3}=0.03 \times \mathrm{PCO}_{2}
$$

The ratio between $\mathrm{HCO}_{3}$ and carbonic acid $\left(\mathrm{HCO}_{3} / \mathrm{H}_{2} \mathrm{CO}_{3}\right)$ was found. The $\mathrm{pH}$ values and the bicarbonate/ carbonic acid ratio is directly related. As the bicarbonate/ carbonic acid ratio increases, the $\mathrm{pH}$ also increases and as the bicarbonate/ carbonic acid ratio decreases, the $\mathrm{pH}$ also decreases which is shown in the graph 3.The changes in $\mathrm{pH}$ and hydrogen ion concentration depends only on the changes in the bicarbonate/carbonic acid ratio.[X] 


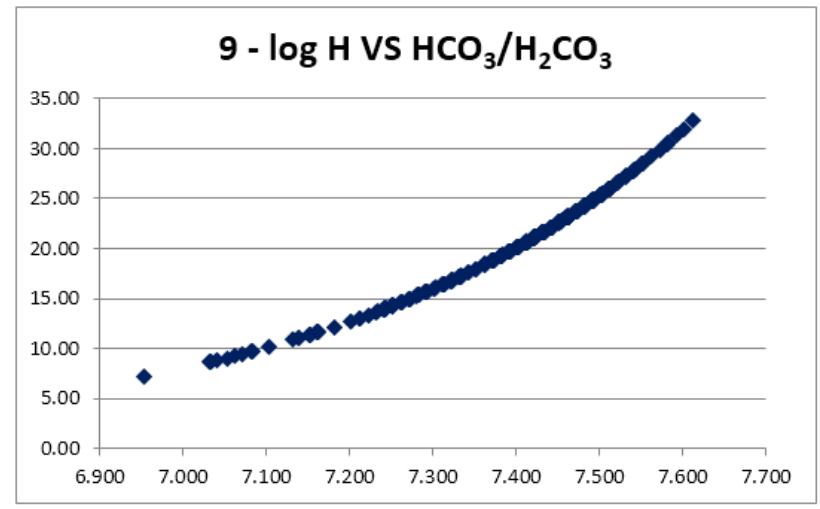

GRAPH3. $\mathrm{X}$ : axis 9 - $\log \mathrm{H}$ VS $\mathrm{Y}$ : axis $\mathrm{HCO}_{3} / \mathrm{H}_{2} \mathrm{CO}_{3}$

\subsection{Newly Derived Ratios}

The bicarbonate/carbonic acid and standard bicarbonate/carbonic acid ratios were calculated. [VII, VIII, IX]

\subsection{Calculation of Ratio 1: (HCO3 /Std HCO3)}

The ratio 1 denotes the ratio between the bicarbonate/carbonic acid and standard bicarbonate/carbonic acid ratios which is numerically the same as the ratio between bicarbonate and standard bicarbonate value. [VII]

Ratio $1=\mathrm{HCO}_{3} / \mathrm{Std}^{\mathrm{HCO}} 3$

\subsection{Calculation of Ratio 2: (HCO3 - STD HCO3) / $\mathrm{H} 2 \mathrm{CO3}$}

Ratio 2 denotes the difference between bicarbonate/carbonic acid and standard bicarbonate/carbonic acid ratio. [VIII]

$$
\text { Ratio } 2=\left(\mathrm{HCO}_{3} / \mathrm{H}_{2} \mathrm{CO}_{3}\right)-\left(\operatorname{Std~} \mathrm{HCO}_{3} / \mathrm{H}_{2} \mathrm{CO}_{3}\right)=\left(\mathrm{HCO}_{3}-\mathrm{Std} \mathrm{HCO}_{3}\right) / \mathrm{H}_{2} \mathrm{CO}_{3}
$$

The ratio between $\left(\mathrm{HCO}_{3}-\mathrm{Standard} \mathrm{HCO}_{3}\right)$ and carbonic acid was calculated and represented by $\left(\mathrm{HCO}_{3}\right.$ - Standard $\left.\mathrm{HCO}_{3}\right) / \mathrm{H}_{2} \mathrm{CO}_{3}$. A Newer parameter that denotes the respiratory influence of $\mathrm{PCO}_{2}$ in changing $\mathrm{pH}$ is given below. [XII]

$$
\left[\mathrm{HCO}_{3} / \mathrm{Std} \mathrm{HCO}_{3}\right]-\left(\mathrm{H}_{2} \mathrm{CO}_{3}-1.2\right) / \mathrm{H}_{2} \mathrm{CO}_{3}
$$

\subsection{Calculation of Ratio 3:}

Ratio 3 is calculated by multiplying ratio 1 and ratio 2. [IX]

$$
\text { Ratio } 3=\left\{\left(\mathrm{HCO}_{3} / \mathrm{Std} \mathrm{HCO}_{3}\right)\right\} \mathbf{X}\left\{\left(\mathrm{HCO}_{3}-\mathrm{Std} \mathrm{HCO}_{3}\right) / \mathrm{H}_{2} \mathrm{CO}_{3}\right\}
$$

\subsection{Calculation of Standard Base Excess:}

The standard base excess(SBE) or the base excess of the extracellular fluid(cBase(ecf)) measured in $\mathrm{mmol} / \mathrm{L}$ or $\mathrm{mEq} / \mathrm{L}$ is calculated by the following formula which is widely used in most Arterial Blood Gas analyser. [VIII, XIII]

$\operatorname{cBase}(\mathrm{ecf})=\mathrm{cHCO}_{3}-24.8+16.2 \times(\mathrm{pH}-7.40)$

\section{RESULTS}

A total of 250 Arterial Blood Gas sample data's were utilized and classified into various acid-base disorder groups based on their normal ranges. The normal reference for arterial blood $\mathbf{p H}$ is 7.35 to 7.45 , for $\mathbf{P C O}_{2}$ is $35-45 \mathrm{~mm}$ of $\mathrm{Hg}$ and for bicarbonate is $22-26 \mathrm{mEq} / \mathrm{L}$ or $\mathrm{mmol} / \mathrm{L}$. The various groups are tabulated in the tables $\mathbf{1}$ and $\mathbf{2}$.

The values of $\mathrm{pH}, \mathrm{PCO}_{2}$, bicarbonate and standard bicarbonate values were noted. The standard base excess, carbonic acid and the ratios 1, 2 and 3 derived using bicarbonate, standard bicarbonate and carbonic acid values all were calculated. The samples of each acid base disturbance groups citing with few examples are tabulated. The table $\mathbf{3}$ shows the samples of Normal and Respiratory acid base disorder cases, table 4 showing the samples of Metabolic acid base disorder cases and the samples of Missellaneous acid base disorder cases are shown in the table 5. 
TABLE1. Normal and Respiratory Acid-base Disorder Groups

\begin{tabular}{|l|l|l|}
\hline GROUP & Type of Acid Base Disorder & Number of Cases \\
\hline Group I & Normal: & $\mathbf{2 5}$ cases \\
\hline Group II & Respiratory acidosis & $\mathbf{3 2}$ cases \\
\cline { 2 - 3 } & Respiratory acidosis $1\left(\mathrm{PCO}_{2}>45 \leq 60 \mathrm{~mm}\right.$ of $\left.\mathrm{Hg}\right)$ & 11 cases \\
\cline { 2 - 3 } & Respiratory acidosis $2\left(\mathrm{PCO}_{2}>60 \leq 80 \mathrm{~mm}\right.$ of $\left.\mathrm{Hg}\right)$ & 14 cases \\
\cline { 2 - 3 } & Respiratory acidosis $3\left(\mathrm{PCO}_{2}>80 \mathrm{~mm}\right.$ of $\left.\mathrm{Hg}\right)$ & 7 cases \\
\hline \multirow{5}{*}{ Group III } & Respiratory alkalosis & $\mathbf{5 3}$ cases \\
\cline { 2 - 3 } & Respiratory alkalosis 1: $\mathrm{PCO}_{2} 31$ to $34 \mathrm{~mm} \mathrm{of} \mathrm{Hg}$ & 16 cases \\
\cline { 2 - 3 } & Respiratory alkalosis 2: $\mathrm{PCO}_{2} 26$ to $30 \mathrm{~mm}$ of Hg & 22 cases \\
\cline { 2 - 3 } & Respiratory alkalosis 3: $\mathrm{PCO}_{2} 21$ to $25 \mathrm{~mm}$ of Hg & 8 cases \\
\cline { 2 - 3 } & Respiratory alkalosis 4: $\mathrm{PCO}_{2} \leq 20 \mathrm{~mm}$ of Hg & 7 cases \\
\hline
\end{tabular}

TABLE2. Metabolic Acid-base Disorder and Missellaneous Groups

\begin{tabular}{|l|l|l|}
\hline GROUP & TYPE OF ACID BASE DISORDER & Number of Cases \\
\hline \multirow{3}{*}{ Group } & Metabolic acidosis & 47 cases \\
\cline { 2 - 3 } & Metabolic acidosis $1\left(\mathrm{HCO}_{3}>18 \leq 22 \mathrm{mmol} / \mathrm{L}\right)$ & 10 cases \\
\cline { 2 - 3 } & Metabolic acidosis $2\left(\mathrm{HCO}_{3}>15 \leq 18 \mathrm{mmol} / \mathrm{L}\right)$ & 12 cases \\
\cline { 2 - 3 } & Metabolic acidosis $3\left(\mathrm{HCO}_{3}>10 \leq 15 \mathrm{mmol} / \mathrm{L}\right)$ & 17 cases \\
\cline { 2 - 3 } & Metabolic acidosis $4\left(\mathrm{HCO}_{3} \leq 10 \mathrm{mmol} / \mathrm{L}\right)$ & 8 cases \\
\hline \multirow{4}{*}{ Group } & Metabolic alkalosis & $\mathbf{3 4}$ cases \\
\cline { 2 - 3 } & Metabolic alkalosis $1\left(\mathrm{HCO}_{3}>40 \mathrm{mmol} / \mathrm{L}\right)$ & 12 cases \\
\cline { 2 - 3 } & Metabolic alkalosis $2\left(\mathrm{HCO}_{3}>30 \leq 40 \mathrm{mmol} / \mathrm{L}\right)$ & 12 cases \\
\cline { 2 - 3 } Group & Metabolic alkalosis $3\left(\mathrm{HCO}_{3}>26 \leq 30 \mathrm{mmol} / \mathrm{L}\right)$ & 10 cases \\
\cline { 2 - 3 } & Missellaneous further divided into Sub-groups & $\mathbf{5 9}$ cases \\
\cline { 2 - 3 } & $\begin{array}{l}\text { Missellaneous 1: } \\
\text { Decreased pH ,increased } \mathrm{PCO}_{2} \text { with decreased } \mathrm{HCO}_{3}\end{array}$ & 11 cases \\
\cline { 2 - 3 } & $\begin{array}{l}\text { Missellaneous 2: } \\
\text { Normal pH, increased } \mathrm{PCO}_{2} \text { with Increased } \mathrm{HCO}_{3}\end{array}$ & 20 cases \\
\cline { 2 - 3 } & $\begin{array}{l}\text { Missellaneous 3: } \\
\text { Normal pH, Decreased } \mathrm{PCO}_{2} \& \text { Decreased } \mathrm{HCO}_{3}\end{array}$ & 28 cases \\
\hline
\end{tabular}

Table3. Samples of Normal and Respiratory acid base disorder Case Values

\begin{tabular}{|c|c|c|c|c|c|c|c|c|c|c|c|}
\hline S.no & pH & $\mathrm{PCO}_{2}$ & $\begin{array}{l}\mathrm{PCO}_{2} \\
-40 \\
\end{array}$ & $\mathrm{H}_{2} \mathrm{CO}_{3}$ & $\begin{array}{l}\left(\mathrm{H}_{2} \mathrm{CO}_{3}-\mathbf{1 . 2}\right) / \\
\mathrm{H}_{2} \mathrm{CO}_{3}\end{array}$ & $\mathrm{HCO}_{3}$ & ${\mathrm{Std} \mathrm{HCO}_{3}}_{3}$ & STD BE & Ratio 1 & $\begin{array}{l}\text { Ratio } \\
2\end{array}$ & Ratio 3 \\
\hline & \multicolumn{11}{|c|}{ Normal } \\
\hline 1 & 7.37 & 43 & 3 & 1.29 & 0.070 & 24.9 & 24.3 & -0.39 & 1.025 & 0.465 & 0.477 \\
\hline 2 & 7.43 & 35 & -5 & 1.05 & -0.143 & 23.2 & 24.4 & -1.11 & 0.951 & -1.143 & -1.087 \\
\hline 3 & 7.4 & 37 & -3 & 1.11 & -0.081 & 22.9 & 23.7 & -1.90 & 0.966 & -0.721 & -0.696 \\
\hline \multirow[t]{2}{*}{4} & 7.41 & 41 & 1 & 1.23 & 0.024 & 26 & 25.5 & 1.36 & 1.020 & 0.407 & 0.414 \\
\hline & \multicolumn{11}{|c|}{ Respiratory acidosis $1\left(\mathrm{PCO}_{2}>45 \leq 60 \mathrm{~mm}\right.$ of $\left.\mathrm{Hg}\right)$} \\
\hline 1 & 7.25 & 51 & 11 & 1.53 & 0.216 & 22.4 & 21.1 & -4.83 & 1.062 & 0.850 & 0.902 \\
\hline 2 & 7.34 & 48 & 8 & 1.44 & 0.167 & 25.9 & 23.1 & 0.13 & 1.121 & 1.944 & 2.180 \\
\hline \multirow[t]{2}{*}{3} & 7.36 & 52 & 12 & 1.56 & 0.231 & 29.4 & 27 & 3.95 & 1.089 & 1.538 & 1.675 \\
\hline & \multicolumn{11}{|c|}{ Respiratory acidosis $2\left(\mathrm{PCO}_{2}>60 \leq 80 \mathrm{~mm}\right.$ of $\left.\mathrm{Hg}\right)$} \\
\hline 1 & 7.17 & 76 & 36 & 2.28 & 0.474 & 27.7 & 23.3 & -0.83 & 1.189 & 1.930 & 2.294 \\
\hline 2 & 7.25 & 62 & 22 & 1.86 & 0.355 & 27.2 & 24.1 & -0.03 & 1.129 & 1.667 & 1.881 \\
\hline \multirow[t]{2}{*}{3} & 7.32 & 74 & 34 & 2.22 & 0.459 & 38.1 & 30.8 & 12.00 & 1.237 & 3.288 & 4.068 \\
\hline & \multicolumn{11}{|c|}{ Respiratory acidosis $3\left(\mathrm{PCO}_{2}>80 \mathrm{~mm}\right.$ of $\left.\mathrm{Hg}\right)$} \\
\hline 1 & 7.2 & 85 & 45 & 2.55 & 0.529 & 33.2 & 26 & 5.16 & 1.277 & 2.824 & 3.605 \\
\hline 2 & 7.27 & 86 & 46 & 2.58 & 0.535 & 39.5 & 31 & 12.59 & 1.274 & 3.295 & 4.198 \\
\hline \multirow[t]{2}{*}{3} & 7.3 & 84 & 44 & 2.52 & 0.524 & 41.3 & 33.8 & 14.88 & 1.222 & 2.976 & 3.637 \\
\hline & \multicolumn{11}{|c|}{ Respiratory alkalosis 1: $\mathrm{PCO}_{2} 31$ to $34 \mathrm{~mm}$ of $\mathrm{Hg}$} \\
\hline 1 & 7.45 & 31 & -9 & 0.93 & -0.290 & 21.5 & 23.7 & -2.49 & 0.907 & -2.366 & -2.146 \\
\hline 2 & 7.51 & 32 & -8 & 0.96 & -0.250 & 25.5 & 27.2 & 2.48 & 0.938 & -1.771 & -1.660 \\
\hline \multirow[t]{2}{*}{3} & 7.49 & 34 & -6 & 1.02 & -0.176 & 25.9 & 27.1 & 2.56 & 0.956 & -1.176 & -1.124 \\
\hline & \multicolumn{11}{|c|}{ Respiratory alkalosis 2: $\mathrm{PCO}_{2} 26$ to $30 \mathrm{~mm}$ of $\mathrm{Hg}$} \\
\hline 1 & 7.45 & 30 & -10 & 0.9 & -0.333 & 20.9 & 23.3 & -3.09 & 0.897 & -2.667 & -2.392 \\
\hline 2 & 7.53 & 30 & -10 & 0.9 & -0.333 & 25.1 & 27.2 & 2.41 & 0.923 & -2.333 & -2.153 \\
\hline \multirow[t]{2}{*}{3} & 7.57 & 27 & -13 & 0.81 & -0.481 & 24.7 & 27.5 & 2.65 & 0.898 & -3.457 & -3.105 \\
\hline & \multicolumn{11}{|c|}{ Respiratory alkalosis 3: $\mathrm{PCO}_{2} 21$ to $25 \mathrm{~mm}$ of $\mathrm{Hg}$} \\
\hline 1 & 7.44 & 25 & -15 & 0.75 & -0.600 & 17 & 20.1 & -7.15 & 0.846 & -4.133 & -3.496 \\
\hline 2 & 7.49 & 22 & -18 & 0.66 & -0.818 & 16.8 & 20.8 & -6.54 & 0.808 & -6.061 & -4.895 \\
\hline 3 & 7.53 & 25 & -15 & 0.75 & -0.600 & 20.9 & 24.3 & -1.79 & 0.860 & -4.533 & -3.899 \\
\hline
\end{tabular}


Revised Graphical Tool for ABG Interpretation using Modified Bicarbonate/Standard Bicarbonate Ratio

\begin{tabular}{|l|l|l|l|l|l|l|l|l|l|l|l|}
\hline 1 & 7.44 & 12 & -28 & 0.36 & -2.333 & 8.2 & 14.9 & -15.95 & 0.550 & -18.611 & -10.242 \\
\hline 2 & 7.47 & 20 & -20 & 0.6 & -1.000 & 14.6 & 18.9 & -9.07 & 0.772 & -7.167 & -5.536 \\
\hline 3 & 7.58 & 18 & -22 & 0.54 & -1.222 & 16.9 & 22.2 & -4.98 & 0.761 & -9.815 & -7.472 \\
\hline
\end{tabular}

Table4. Samples of Metabolic acid base disorder Case Values

\begin{tabular}{|c|c|c|c|c|c|c|c|c|c|c|c|}
\hline S.no & pH & $\mathrm{PCO}_{2}$ & $\begin{array}{l}\mathrm{PCO}_{2} \\
-40\end{array}$ & $\mathrm{H}_{2} \mathrm{CO}_{3}$ & $\begin{array}{l}\left(\mathrm{H}_{2} \mathrm{CO}_{3}-1.2\right) / \\
\mathrm{H}_{2} \mathrm{CO}_{3}\end{array}$ & $\mathrm{HCO}_{3}$ & Std $\mathrm{HCO}_{3}$ & STD BE & Ratio 1 & Ratio 2 & Ratio 3 \\
\hline \multicolumn{12}{|c|}{ Metabolic acidosis $1\left(\mathrm{HCO}_{3}>18 \leq 22 \mathrm{mmol} / \mathrm{L}\right)$} \\
\hline 1 & 7.36 & 34 & -6 & 1.02 & -0.176 & 19.2 & 20.8 & -6.25 & 0.923 & -1.569 & -1.448 \\
\hline 2 & 7.32 & 37 & -3 & 1.11 & -0.081 & 19.1 & 19.9 & -7.00 & 0.960 & -0.721 & -0.692 \\
\hline 3 & 7.22 & 45 & 5 & 1.35 & 0.111 & 18.4 & 17.6 & -9.32 & 1.045 & 0.593 & 0.620 \\
\hline \multicolumn{12}{|c|}{ Metabolic acidosis $2\left(\mathrm{HCO}_{3}>15 \leq 18 \mathrm{mmol} / \mathrm{L}\right)$} \\
\hline 1 & 7.35 & 32 & -8 & 0.96 & -0.250 & 17.7 & 19.4 & -7.91 & 0.912 & -1.771 & -1.616 \\
\hline 2 & 7.28 & 36 & -4 & 1.08 & -0.111 & 16.9 & 17.9 & -9.84 & 0.944 & -0.926 & -0.874 \\
\hline 3 & 7.23 & 42 & 2 & 1.26 & 0.048 & 17.6 & 17.3 & -9.95 & 1.017 & 0.238 & 0.242 \\
\hline \multicolumn{12}{|c|}{ Metabolic acidosis $3\left(\mathrm{HCO}_{3}>10 \leq 15 \mathrm{mmol} / \mathrm{L}\right)$} \\
\hline 1 & 7.36 & 25 & -15 & 0.75 & -0.600 & 14.1 & 17.4 & -11.35 & 0.810 & -4.400 & -3.566 \\
\hline 2 & 7.23 & 30 & -10 & 0.9 & -0.333 & 12.6 & 14.1 & -14.95 & 0.894 & -1.667 & -1.489 \\
\hline 3 & 7.15 & 42 & 2 & 1.26 & 0.048 & 14.6 & 14.4 & -14.25 & 1.014 & 0.159 & 0.161 \\
\hline \multicolumn{12}{|c|}{ Metabolic acidosis $4\left(\mathrm{HCO}_{3} \leq 10 \mathrm{mmol} / \mathrm{L}\right)$} \\
\hline 1 & 7.3 & 18 & -22 & 0.54 & -1.222 & 8.9 & 12.8 & -17.52 & 0.695 & -7.222 & -5.022 \\
\hline 2 & 7.24 & 22 & -18 & 0.66 & -0.818 & 9.4 & 12.1 & -17.99 & 0.777 & -4.091 & -3.178 \\
\hline 3 & 7.13 & 29 & -11 & 0.87 & -0.379 & 9.6 & 10.8 & -19.57 & 0.889 & -1.379 & -1.226 \\
\hline \multicolumn{12}{|c|}{ Metabolic alkalosis $1\left(\mathrm{HCO}_{3}>40 \mathrm{mmol} / \mathrm{L}\right)$} \\
\hline 1 & 7.59 & 52 & 12 & 1.56 & 0.231 & 49.9 & 44.4 & 28.18 & 1.124 & 3.526 & 3.962 \\
\hline 2 & 7.45 & 60 & 20 & 1.8 & 0.333 & 41.7 & 36.4 & 17.71 & 1.146 & 2.944 & 3.373 \\
\hline 3 & 7.49 & 65 & 25 & 1.95 & 0.385 & 49.5 & 40.4 & 26.16 & 1.225 & 4.667 & 5.718 \\
\hline \multicolumn{12}{|c|}{ Metabolic alkalosis $2\left(\mathrm{HCO}_{3}>30 \leq 40 \mathrm{mmol} / \mathrm{L}\right)$} \\
\hline 1 & 7.5 & 46 & 6 & 1.38 & 0.130 & 35.9 & 34 & 12.72 & 1.056 & 1.377 & 1.454 \\
\hline 2 & 7.49 & 52 & 12 & 1.56 & 0.231 & 39.6 & 35.6 & 16.26 & 1.112 & 2.564 & 2.852 \\
\hline 3 & 7.44 & 54 & 14 & 1.62 & 0.259 & 36.7 & 32.6 & 12.55 & 1.126 & 2.531 & 2.849 \\
\hline \multicolumn{12}{|c|}{ Metabolic alkalosis $3\left(\mathrm{HCO}_{3}>26 \leq 30 \mathrm{mmol} / \mathrm{L}\right)$} \\
\hline 1 & 7.48 & 35 & -5 & 1.05 & -0.143 & 26.1 & 27.1 & 2.60 & 0.963 & -0.952 & -0.917 \\
\hline 2 & 7.54 & 35 & -5 & 1.05 & -0.143 & 29.9 & 30.5 & 7.37 & 0.980 & -0.571 & -0.560 \\
\hline 3 & 7.45 & 40 & 0 & 1.2 & 0.000 & 27.7 & 27.7 & 3.71 & 1.000 & 0.000 & 0.000 \\
\hline
\end{tabular}

Table5. Samples of Missellaneous acid base disorder Case Values

\begin{tabular}{|c|c|c|c|c|c|c|c|c|c|c|c|}
\hline S.no & pH & $\mathrm{PCO}_{2}$ & $\begin{array}{l}\mathrm{PCO}_{2} \\
-40 \\
\end{array}$ & $\mathrm{H}_{2} \mathrm{CO}_{3}$ & $\begin{array}{l}\left(\mathrm{H}_{2} \mathrm{CO}_{3-1.2}\right) / \\
\mathrm{H}_{2} \mathrm{CO}_{3}\end{array}$ & $\mathrm{HCO}_{3}$ & $\mathrm{Std} \mathrm{HCO}_{3}$ & STD BE & Ratio 1 & $\begin{array}{l}\text { Ratio } \\
\mathbf{2} \\
\end{array}$ & Ratio 3 \\
\hline \multicolumn{12}{|c|}{ Missellaneous 1: Decreased pH ,increased $\mathrm{PCO}_{2}$ with decreased $\mathrm{HCO}_{3}$} \\
\hline 1 & 7.15 & 46 & 6 & 1.38 & 0.130 & 16 & 15.1 & -12.85 & 1.060 & 0.652 & 0.691 \\
\hline 2 & 7.07 & 63 & 23 & 1.89 & 0.365 & 18.3 & 15.5 & -11.85 & 1.181 & 1.481 & 1.749 \\
\hline 3 & 7.03 & 75 & 35 & 2.25 & 0.467 & 19.8 & 16 & -10.99 & 1.238 & 1.689 & 2.090 \\
\hline \multicolumn{12}{|c|}{ Missellaneous 2: Normal pH, increased $\mathrm{PCO}_{2}$ with Increased $\mathrm{HCO}_{3}$} \\
\hline 1 & 7.38 & 50 & 10 & 1.5 & 0.200 & 29.6 & 27.6 & 4.48 & 1.072 & 1.333 & 1.430 \\
\hline 2 & 7.4 & 59 & 19 & 1.77 & 0.322 & 36.5 & 32.6 & 11.70 & 1.120 & 2.203 & 2.467 \\
\hline 3 & 7.42 & 64 & 24 & 1.92 & 0.375 & 41.5 & 36.3 & 17.02 & 1.143 & 2.708 & 3.096 \\
\hline \multicolumn{12}{|c|}{ Missellaneous 3: Normal pH, Decreased $\mathrm{PCO}_{2} \&$ Decreased $\mathrm{HCO}_{3}$} \\
\hline 1 & 7.38 & 18 & -22 & 0.54 & -1.222 & 11.7 & 16.9 & -13.42 & 0.692 & -9.630 & -6.667 \\
\hline 2 & 7.4 & 25 & -15 & 0.75 & -0.600 & 16.2 & 19.5 & -8.60 & 0.831 & -4.400 & -3.655 \\
\hline 3 & 7.42 & 26 & -14 & 0.78 & -0.538 & 15.4 & 18.4 & -9.08 & 0.837 & -3.846 & -3.219 \\
\hline
\end{tabular}

\section{DISCUSSION}

Arterial blood gas (ABG) analysis plays a vital role in the management of critically ill patients but the interpretation is sometimes an arduous task if the acid-base disturbances are complex. SiggaardAndersen chart (S-A chart) developed by Siggaard-Andersen is considered the standard diagram for the diagnosis of acid-base balance disorder. It is a two-axial diagram that plots $\mathrm{pH}$ as a linear function of $\log \mathrm{PaCO}_{2}$ as derived by the Henderson-Hasselbalch equation. But the major disadvantage of the chart is that it cannot diagnose many pairs of $\mathrm{pH}-\mathrm{PCO}_{2}$ values that have not been adopted in the everyday clinical practice. [XIV - XVI]

Davenport or Bicarbonate-pH diagram is a graphical tool used to depict the respiratory and metabolic acid-base disturbances in a three dimensional surface. [XVII] The $\mathbf{x}$-axis represents $\mathbf{p H}$ and the $\mathbf{y}$-axis represents plasma bicarbonate concentration and the curved lines known as isopleths, represent the $\mathrm{PCO}_{2}$ values derived using the Henderson hasselbach equation. Each isopleth $\mathrm{PCO}_{2}$ curved line has a 
fixed $\mathrm{PCO}_{2}$ value for a given variable $\mathrm{pH}$ and bicarbonate Concentration calculated using the modified Henderson equation. The Davenport diagram is rarely used in the clinical setting. [XVII]

Grogono diagram is a new two-axial diagram consists of $\mathbf{2 3}$ clearly defined areas, each one representing a particular acid-base balance disorder. The $\mathbf{P C O} \mathbf{O}_{2}$ representing the respiratory component of the acid base disorder is plotted in the horizontal axis and the standard base denoting the metabolic component of the acid base disorder in plotted in the vertical axis is shown in the figure 1. This newer diagrammatic approach to the diagnosis of acid-base balance disorders although superior to the S-A chart, cannot be safely used for the diagnosis of acid-base balance disorders in everyday clinical practice, because it has been shown to provide inaccurate diagnoses in at least $25 \%$ of the cases. Grogono diagram, despite its higher diagnostic agreement compared to the classic Siggaard-Andersen diagram, is not superior to the Oxygen Status Algorithm software program. [XVIII]

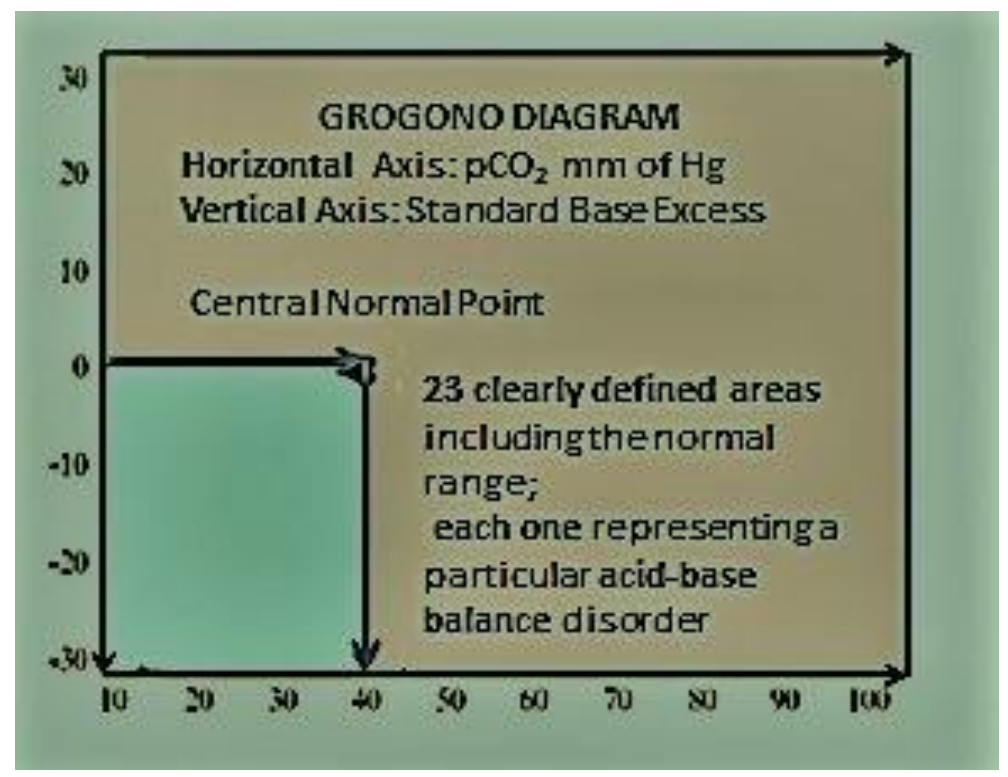

FIGURE1. Grogono Diagram

The Oxygen-Status-Algorithm (OSA) Software was developed by the Radiometer-Copenhagen Company on the basis of the diagram and work done by Siggaard-Andersen. This software was installed in all blood gas analysers manufactured by Radiometer-Copenhagen. [XVIII]Nevertheless, the enormous technological advance in laboratory methods and instruments that has occurred in the last decades has not brought a respective advance in the field of diagnosis. [XVIII]

Recently a novel graphical tool was developed by Rajini Samuel (Current Author) for ABG interpretation to analyse the various acid-base disturbances in a four quadrant graphical method by using bicarbonate, standard bicarbonate, carbonic acid and standard base excess values. [VIII] The calculated bicarbonate concentration derived from Modified Henderson equation is a variable parameter because it changes with alterations in the values of $\mathrm{PCO}_{2}$. [VII - IX]

In respiratory acidosis (due to hypoventilation) $\mathrm{PCO}_{2}$ retention occurs and in respiratory alkalosis (due to hyperventilation) $\mathrm{PCO}_{2}$ value is decreased. The bicarbonate value is increased in respiratory acidosis and decreased in respiratory alkalosis. So, the difference between bicarbonate and standard bicarbonate value is positive for respiratory acidosis and negative for respiratory alkalosis. If the acidbase disorder is purely metabolic without respiratory compensation, then the bicarbonate and standard bicarbonate values are more or less close. If the metabolic disorder is compensated by respiratory mechanisms, then the two values alter and deviate from each other. [VII - IX]

The relation between $\mathrm{PCO}_{2}$ and the ratio $1\left(\mathrm{HCO}_{3} / \mathrm{Std} \mathrm{HCO}_{3}\right)$ depicted in the graph 4 clearly shows that as the $\mathrm{PCO}_{2}$ increases, the ratio 1 also increases and afterwards the curve slightly flattens.[VII] The correlation between $\mathrm{PCO}_{2}$ and the ratio $2\left(\mathrm{HCO}_{3}-\mathrm{Std} \mathrm{HCO}_{3}\right) / \mathrm{H}_{2} \mathrm{CO}_{3}$ depicted in the graph 5 clearly shows that as the $\mathrm{PCO}_{2}$ increases, the ratio 2 also increases and afterwards the curve flattens.[VII,VIII] At $\mathrm{PCO}_{2} 40 \mathrm{mmHg}$, both the bicarbonate and standard bicarbonate values are equal and so the difference is zero. 


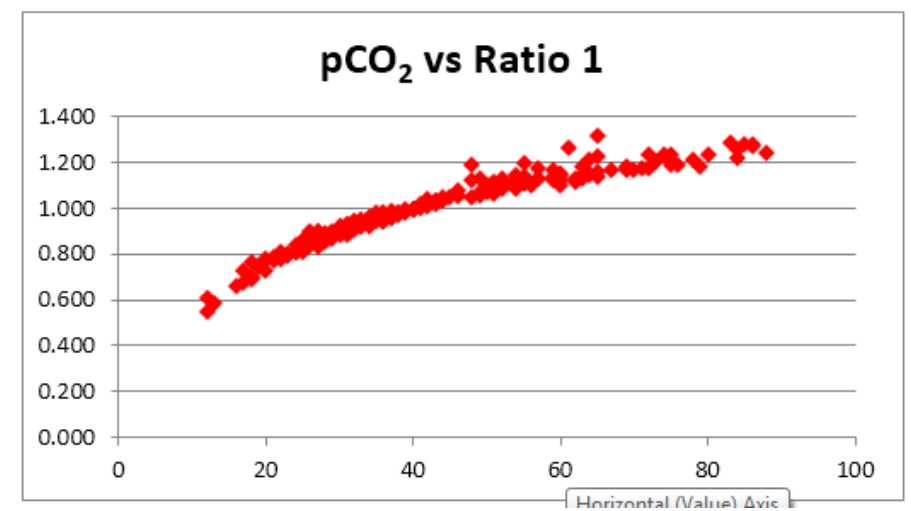

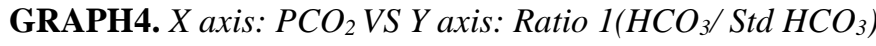

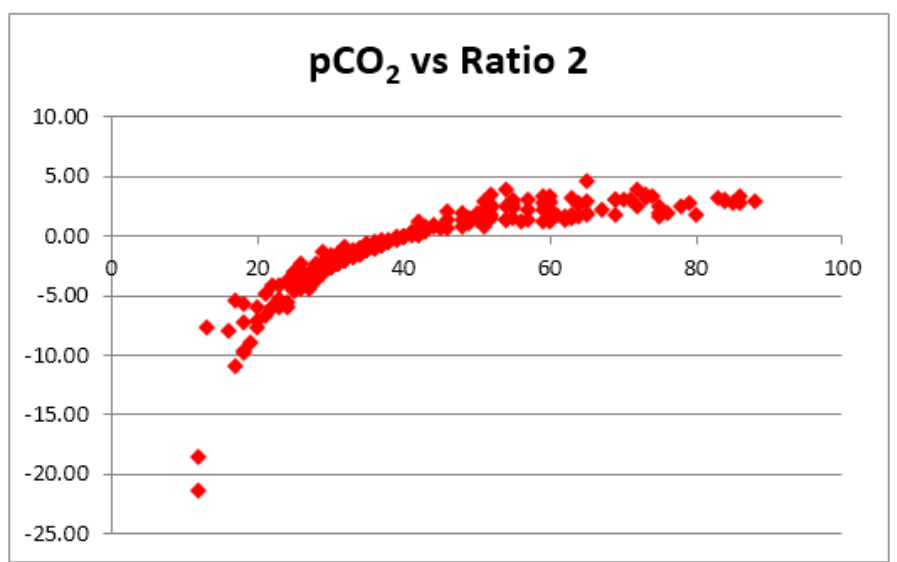

GRAPH5. $\mathrm{X}$ axis: $\mathrm{PCO}_{2}$ VS $Y$ axis: Ratio 2

The ratio $1\left(\mathbf{H C O}_{3} /\right.$ Std $\left.\mathbf{H C O}_{3}\right)$ values are greater $(>\mathbf{1})$ for increased $\mathrm{PCO}_{2}$ and lesser $(<\mathbf{1})$ for decreased $\mathrm{PCO}_{2}$. The ratio 2 values are positive for greater ratio 1 values and negative for lesser ratio 1 values. Obviously, the value of ratio 2 is zero if the ratio 1 value is one. Ratio 2 values are negative for lower $\mathrm{PCO}_{2}$ (lesser than $40 \mathrm{mmHg}$ ) and positive for higher $\mathrm{PCO}_{2}$ (more than $40 \mathrm{mmHg}$ ). These newer ratios derived using bicarbonate, standard bicarbonate and carbonic acid values render some clues regarding the disturbances affecting the acid-base homeostasis. [VII] A Newer parameter that denotes the respiratory influence of $\mathrm{PCO}_{2}$ in changing $\mathrm{pH}$ is given by the following relation. [XII]

\section{$\left[\mathrm{HCO}_{3} / \mathrm{Std} \mathrm{HCO}_{3}\right]-\left(\mathrm{H}_{2} \mathrm{CO}_{3}-1.2\right) / \mathrm{H}_{2} \mathrm{CO}_{3}$}

From the graph 4, the first part of the above relation $\left(\mathrm{HCO}_{3} / \mathbf{S t d} \mathbf{H C O}_{3}\right)$ is very clear that the respiratory influence of $\mathrm{PCO}_{2}$ in changing $\mathrm{pH}$ through bicarbonate is a variable one depending on acute or chronic conditions or compensations. [XII] The second part of the relation $\left(\left(\mathbf{H}_{2} \mathbf{C O}_{3}\right.\right.$ 1.2)/ $\mathrm{H}_{2} \mathrm{CO}_{3}$ ) denotes that the respiratory influence of $\mathrm{PCO}_{2}$ in changing the $\mathrm{pH}$ through carbonic acid is a constant which is clearly depicted in the graph 6.

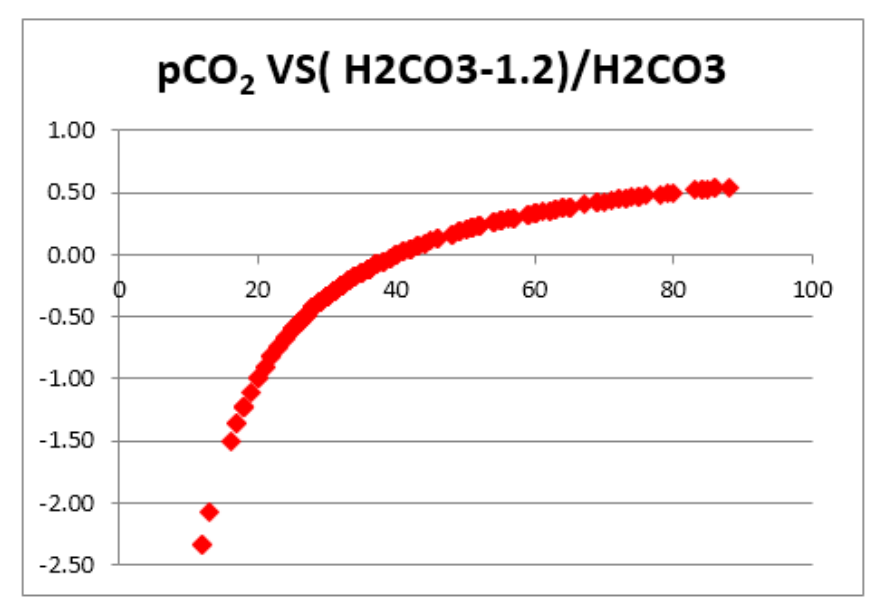

GRAPH6. $\mathrm{X}$ axis: $\mathrm{PCO}_{2} \mathrm{VS} \mathrm{Y}$ axis: $\left(\mathrm{H}_{2} \mathrm{CO}_{3}-1.2\right) / \mathrm{H}_{2} \mathrm{CO}_{3}$ 
A novel four quadrant graphical tool was developed by the Current Author for $\mathrm{ABG}$ interpretation using standard base excess in the $\mathrm{x}$ axis and the ratio $2\left(\mathrm{HCO}_{3}-\mathrm{Std} \mathrm{HCO}_{3}\right) / \mathrm{H}_{2} \mathrm{CO}_{3}$ values in the $\mathrm{y}$ axis to analyse the various acid-base disturbances in a graphical method.[VIII] The normal range for standard base excess is $\mathbf{2} \mathbf{2} \mathbf{~ m m o l} / \mathbf{L}$. If the value is $>\mathbf{2} \mathbf{~ m m o l} / \mathbf{L}$ then it denotes metabolic alkalosis and if the value is $<\mathbf{- 2} \mathbf{~} \mathbf{~ m m o l} / \mathbf{L}$ then it denotes metabolic acidosis (base deficit). The acid-base disorders can be classified and plotted in the $\mathbf{4}$ quadrant graph. Each acid-base disorders will occupy any of the 4 quadrant and the normal arterial blood gas analysis reports will be seen around the centre of the graph.[VIII] This novel four quadrant graphical method will serve as a newer graphical tool that may provide a rough guide and help in easier and quicker interpretation of $\mathrm{ABG}$ reports which is clearly shown in the table 6.

TABLE6. ACID BASE DISORDERS IN A FOUR QUADRANT GRAPHICAL TOOL

\begin{tabular}{|c|c|c|c|c|}
\hline \multicolumn{5}{|c|}{ Various acid-base disorders plotted will occupy any of the 4 quadrant. } \\
\hline \multirow{2}{*}{$\begin{array}{l}\text { PLOTTED } \\
\text { AREA }\end{array}$} & \multicolumn{4}{|c|}{ Quadrant in the Graphical Tool } \\
\hline & $\begin{array}{l}\mathbf{1}^{\text {st }} \text { quadrant both } \mathrm{x} \\
\text { axis and } \mathrm{y} \text { axis } \\
\text { are positive }\end{array}$ & $\begin{array}{l}2^{\text {nd }} \text { quadrant } \\
\mathrm{x} \text { axis positive and } \mathrm{y} \\
\text { axis negative }\end{array}$ & $\begin{array}{l}\mathbf{3}^{\text {rd }} \text { quadrant both } \\
\mathrm{x} \text { axis and } \mathrm{y} \\
\text { axis are negative }\end{array}$ & $\begin{array}{l}4^{\text {th }} \text { quadrant } \\
\mathrm{x} \text { axis negative and } \\
\mathrm{y} \text { axis positive }\end{array}$ \\
\hline $\begin{array}{l}\text { Towards } \\
\text { X: Axis }\end{array}$ & $\begin{array}{l}\text { Metabolic } \\
\text { Alkalosis }\end{array}$ & $\begin{array}{l}\text { Metabolic } \\
\text { Alkalosis }\end{array}$ & $\begin{array}{l}\text { Metabolic } \\
\text { Acidosis }\end{array}$ & Metabolic Acidosis \\
\hline $\begin{array}{l}\text { Towards } \\
\text { Y: Axis }\end{array}$ & $\begin{array}{l}\text { Respiratory } \\
\text { Acidosis }\end{array}$ & Respiratory Alkalosis & $\begin{array}{l}\text { Respiratory } \\
\text { Alkalosis }\end{array}$ & Respiratory Acidosis \\
\hline \multicolumn{5}{|c|}{$\begin{array}{l}\text { Normal Cases around the centre of the graph. } \\
\text { Simple acid base disorders: Towards Single Axis (either x axis or y axis) } \\
\text { Combined acid base disturbances (compensations or mixed disorders): } \\
\text { In between them (x axis and y axis) }\end{array}$} \\
\hline
\end{tabular}

A minor drawback of this graphical tool is that this may not clearly demarcate the different higher levels of $\mathrm{PCO}_{2}$ values. [I, XIX] Although the ratio2 $\left(\mathrm{HCO}_{3}\right.$ - Standard $\left.\mathrm{HCO}_{3}\right) / \mathrm{H}_{2} \mathrm{CO}_{3}$ differentiate the respiratory acidosis and respiratory alkalosis, it may not clearly differentiate the different $\mathrm{PCO}_{2}$ levels. But this can be rectified in 3-dimensional graph if $\mathbf{P C O}_{2}$ values are included in the third axis. The parameter $\left(\mathbf{P C O}_{2}-\mathbf{4 0} \mathbf{~ m m}\right.$ of $\left.\mathbf{H g}\right)$ should be taken in the third axis, because the ratio $\left(\mathbf{H C O}_{3^{-}}\right.$ Standard $\left.\mathrm{HCO}_{3}\right) / \mathrm{H}_{2} \mathrm{CO}_{3}$ is zero at $\mathrm{PCO}_{2} 40 \mathrm{~mm}$ of $\mathrm{Hg}$, so that the zero central point is common to all the 3 parameters of the three axes.[I,XIX] As the $\mathrm{PCO}_{2}$ increases, ratio $2\left\{\left(\mathrm{HCO}_{3}-\right.\right.$ Standard $\left.\mathrm{HCO}_{3}\right) / \mathrm{H}_{2} \mathrm{CO}_{3}$ \} also increases and afterwards the curve flattens.[IX] But this flattening is slightly reduced and the curve is slightly steeper if ratio 3 ( multiplying ratio 1 with ratio 2 ) is utilized instead of ratio 2. (shown in the graph 7 which can be compared with graph 5)

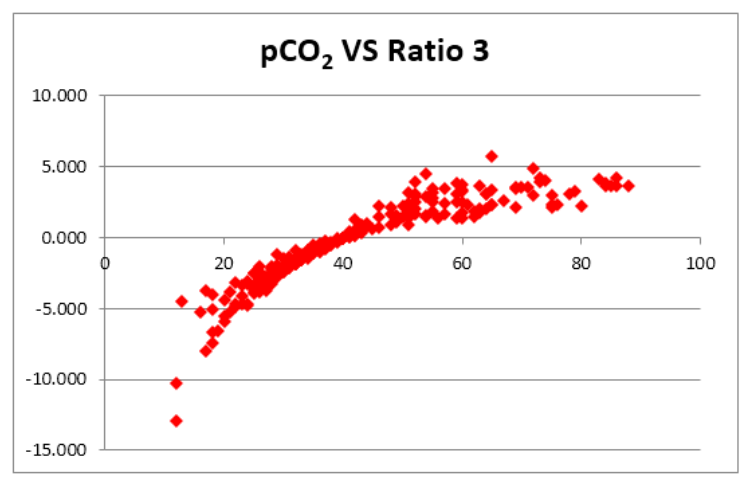

GRAPH7. $\mathrm{X}$ axis: $\mathrm{PCO}_{2}$ VS $Y$ axis: Ratio 3

In the current study, 250 arterial blood gas sample cases were classified into various acid base disorders namely normal, respiratory acidosis, respiratory alkalosis, metabolic acidosis, metabolic alkalosis and missellaneous cases based on the values of $\mathrm{pH}, \mathrm{PCO}_{2}$, bicarbonate and base excess which are clearly shown in the tables $\mathbf{1}$ and $\mathbf{2}$. The respiratory acidosis and alkalosis were divided into sub-groups based on the values of $\mathrm{PCO}_{2}$. Similarly, metabolic acidosis and alkalosis were classified into sub-groups based on the bicarbonate values. The missellanous cases were divided into subgroups based on the values of $\mathrm{pH}, \mathrm{PCO}_{2}$ and bicarbonate.

The revised graphical tool for ABG interpretation can be constructed in a 3-dimensional surface by using standard base excess values in the $\mathrm{x}$ axis, ratio 3 values in the second axis and the parameter 
$\left(\mathrm{PCO}_{2}-40 \mathrm{~mm}\right.$ of $\left.\mathbf{H g}\right)$ in the third axis to analyse the various acid-base disturbances. For practical convenience, in this research article, the 3-dimensional graph is represented in two graphs (2dimensional graph).

A graphical tool constructed using standard base excess in the $\mathrm{x}$ axis and the ratio 3 values in the $\mathrm{y}$ axis for the various acid base disorder groups (250 cases divided into 18 different acid base disorder groups) is clearly shown in the graph 8. The relation between the parameter $\left(\mathrm{PCO}_{2}-40 \mathrm{~mm}\right.$ of $\left.\mathrm{Hg}\right)$ and the ratio 3 value is clearly shown in the graph 9.

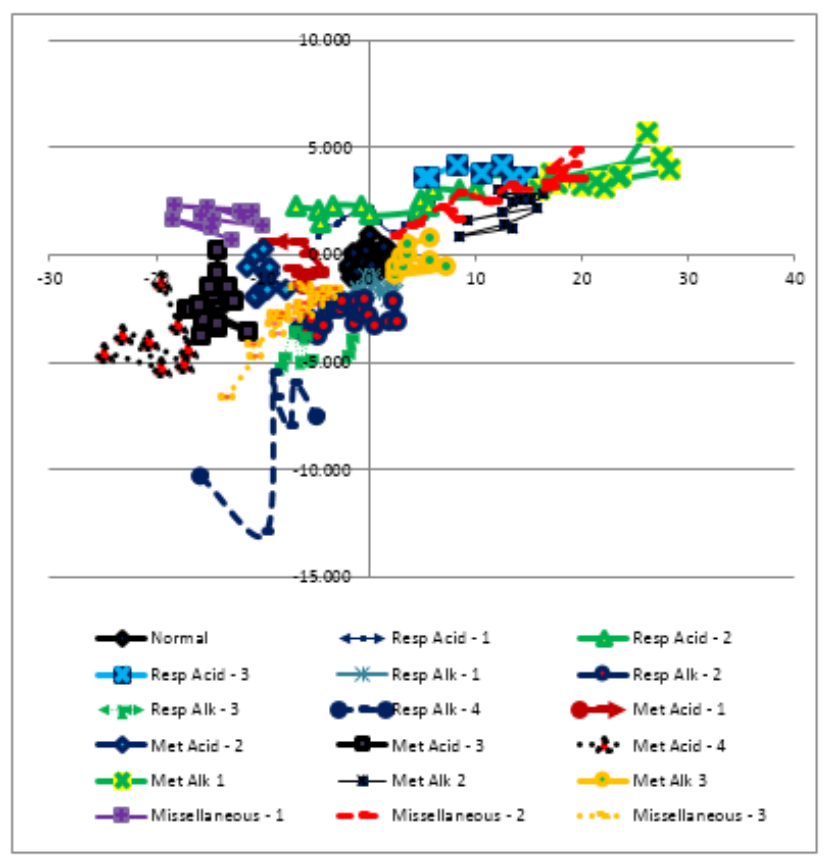

GRAPH8. Four Quadrant Graphical Tool - X axis: Std BE VS Y axis: Ratio 3

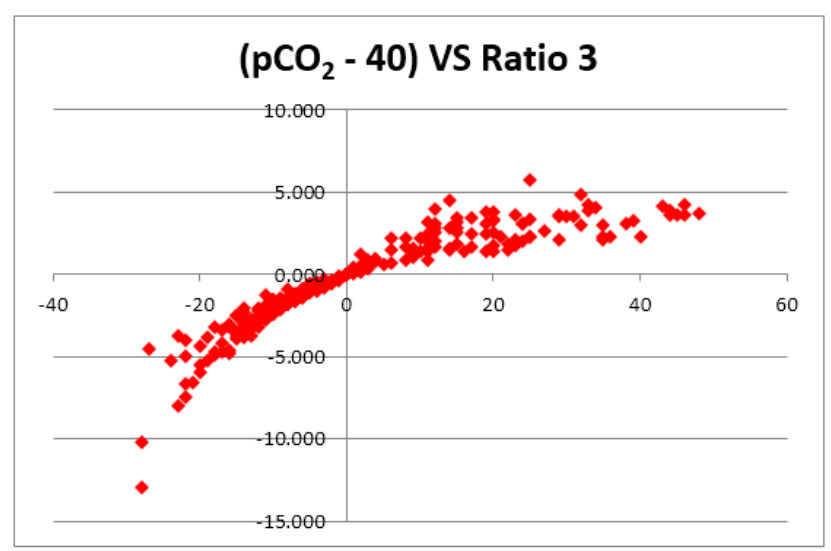

GRAPH9. $X$ axis: $\left(\mathrm{PCO}_{2}-40\right)$ VS Y axis: Ratio 3

A 3-dimensional graphical tool( four quadrant in 2-dimension and it becomes $\mathbf{8}$ in 3-dimension) can be constructed by the combination of the graphs 8 and 9 using standard base excess, ratio 3 and $\left(\mathrm{PCO}_{2}-40 \mathbf{~ m m}\right.$ of $\left.\mathbf{H g}\right)$ values of the various acid-base disturbances in the three ( $\mathrm{x}$ axis , $\mathrm{y}$ axis and $\mathrm{z}$ axis) perpendicular axis respectively to analyse the different acid -base disorder groups. The advancement in the field of diagnosis of acid base disorders were very minimal in the last decades. This recently proposed four quadrant graphical tool by the current author which is revised in this current research study article may fulfil the requirements for a graphical visualization method to be widely applied in clinical practice.

\section{Conclusion}

The study concludes that this revised novel diagnostic graphical tool which clearly demarcates the various acid-base disorders in different quadrants may serve as a supporting tool for better understanding and quicker interpretation to overcome the challenging and arduous task of Arterial Blood Gas (ABG) interpretation. 


\section{REFERENCES}

[1] Rajini Samuel A Graphical Representation For Aiding Arterial Blood Gas Interpretation Using NonRespiratory And Respiratory pH WJPMR, 2018,4(12), 192-202

[2] Dheeraj Kapoor, Meghana Srivastava, and Pritam Singh, Point of care blood gases with electrolytes and lactates in adult emergencies Int J Crit Illn Inj Sci. 2014 Jul-Sep; 4(3): 216-222.

[3] Barnette, L. \& Kautz, D.D. Creative ways to teach arterial blood gas interpretation. Dimensions of Critical Care Nursing (DCCN), 2013; 32(2): 84-87.

[4] Doig AK, Albert RW, Syroid ND, Moon S, Agutter JA. Graphical arterial blood gas visualization tool supports rapid and accurate data interpretation Comput Inform Nurs, 2011; 29(4): 53-60

[5] Pramod Sood, Gunchan Paul, and Sandeep Puri Interpretation of arterial blood gas Indian J Crit Care Med. 2010 Apr-Jun; 14(2): 57-64.

[6] Bartter TC, Abouzgheib WB, Pratter MR, Irwin RS. In: Irwin and Rippe's Intensive Care Medicine. 6th edi. Lippincott: Williams and Wilkins Publishers; 2008. Respiratory Failure-Part 1; pp. 485-9.

[7] Rajini Samuel T Application of standard bicarbonate/carbonic acid ratio in arterial blood gas analysis International Journal of Clinical Biochemistry and Research, 2018;5(2):314 - 320

[8] Samuel R. A Graphical Tool for Arterial Blood Gas Interpretation using Standard Bicarbonate and Base Excess. Indian J Med Biochem, 2018; 22(1): 85-89

[9] Rajini Samuel T Application Of Modified Bicarbonate/Standard Bicarbonate Ratio In Arterial Blood Gas Interpretation International Journal Of Scientific Research-2019 ; 8(3): 60-63

[10] Rajini Samuel, Ilanchezian, Balaji Rajagopalan .Application of Modified Henderson Equation in ABG Interpretation. Int. J. Pharm. Sci. Rev. Res., 2016; 37(2):169-177

[11] Rajini Samuel T, Balaji Rajagopalan, Uma Maheshwari. A novel contemporary perspective teaching method for interpretation of various acid base disorders citing with examples. International Journal of Contemporary Medical Research 2019;6(3):C10-C14.

[12] Rajini Samuel T Application and Inter-Relationship of Non-Respiratory Hydrogen Ion Concentration in Acid-Base Balance Theory International Journal of Clinical Chemistry and Laboratory Medicine (IJCCLM), 2018; 4(3): 1-13.

[13] Rajini Samuel,Vyshnavi, Vanaja, Ragashree, Balaji Rajagopalan Graphical Analysis of Arterial Blood Gas Analysis Using Standard Base Excess, Int. J. Pharm. Sci. Rev. Res., 2017; 46(1) : 223-228

[14] Siggaard-Andersen O. Acid-base balance. In: Boston GEO, editor. Encyclopedia of respiratory medicine. Amsterdam: Academic Press; 2006. p. 5-10

[15] H. G. MORGAN ACID-BASE BALANCE IN BLOOD BRITISH JOURNAL OF ANAESTHESIA (1969), 41: 196- 212

[16] N. THEAKOS, A. LOUKOS*, M. VASSILIOU**, M. MOUKAS*, M. ZAKA* and P.K. BEHRAKIS $\mathrm{pH}-\log \mathrm{PaCO} 2$ diagram for the diagnostic approach of simple acid-base disorders 2nd Mediterranean Congress on THORACIC DISEASES Athens, Greece 4-7 March 1998

[17] Davenport, Horace W. (1974). The ABC of Acid-Base Chemistry: The Elements of Physiological BloodGas Chemistry for Medical Students and Physicians (Sixth ed.). Chicago: The University of Chicago Press.

[18] Panagiotis Behrakis, Miltos Vasileiou, Loukos A., Theakos N. Latest developments in graphic diagnostic approach of arterial blood gases disturbances Pneumon 2004, 17(2):150-158.

[19] T. Rajini Samuel Chapter Who Is Balancing: Is It RBC or Acid-Base Status? Intech Open Publisher; pages 1-15 DOI: http://dx.doi.org/10.5772/intechopen.84768

Citation: Dr.T. Rajini Samuel M.D (2019),. "Revised Graphical Tool for ABG Interpretation using Modified Bicarbonate/Standard Bicarbonate Ratio". International Journal of Clinical Chemistry and Laboratory Medicine (IJCCLM), 5(3), pp.19-29, DOI: http://dx.doi.org/10.20431/2455-7153.0503003.

Copyright: (C) 2019 Authors. This is an open-access article distributed under the terms of the Creative Commons Attribution License, which permits unrestricted use, distribution, and reproduction in any medium, provided the original author and source are credited. 